\title{
Association of Race and Change in Ankle-Brachial Index: The Atherosclerosis Risk in Communities (ARIC) Cohort
}

\author{
Ericha Gretchen Franey,2, Donna Kritz-Silverstein², Erin L. Richard ${ }^{1,2}$, John E. Alcaraz', \\ Caroline M. Nievergelt ${ }^{3}$, Richard A. Shaffer ${ }^{1}$, Vibha Bhatnagar ${ }^{2}$ \\ ${ }^{1}$ Graduate School of Public Health, San Diego State University, San Diego, CA, USA \\ ${ }^{2}$ Department of Family Medicine and Public Health, University of California San Diego, La Jolla, CA, USA \\ ${ }^{3}$ Department of Psychiatry, University of California San Diego, La Jolla, CA, USA \\ Email: *ericha_anthony@yahoo.com,dsilverstein@ucsd.edu
}

How to cite this paper: Franey, E.G., Kritz-Silverstein, D., Richard, E.L., Alcaraz, J.E., Nievergelt, C.M., Shaffer, R.A. and Bhatnagar, V. (2020) Association of Race and Change in Ankle-Brachial Index: The Atherosclerosis Risk in Communities (ARIC) Cohort. Advances in Aging Research, 9, 77-93

https://doi.org/10.4236/aar.2020.95007

Received: September 5, 2020

Accepted: September 27, 2020

Published: September 30, 2020

Copyright $\odot 2020$ by author(s) and Scientific Research Publishing Inc. This work is licensed under the Creative Commons Attribution International License (CC BY 4.0).

http://creativecommons.org/licenses/by/4.0/

(c) (i) Open Access

\begin{abstract}
Objective: This study evaluates the association of self-reported race with change in ankle-brachial index (ABI) over time and modification of this association by paraoxonase gene ( $P O N 1, P O N 2$ and $P O N 3)$ single nucleotide polymorphisms (SNPs). Methods: This longitudinal study included 11,992 ( $=2952$ Black, $\mathrm{N}=9040$ White) participants from the Atherosclerosis Risk in Communities (ARIC) cohort with PON genotyping. Mixed-effects models examined whether race was associated with change in $\mathrm{ABI}$ over time after adjustment for known peripheral artery disease (PAD) risk factors. Results: Change in ABI over time differed between Whites and Blacks (race-time interaction, $\mathrm{p}<$ 0.0001). Stratified analyses showed that ABI values were better in both Blacks and Whites who completed high school or more education compared to those who completed less education. None of the PON SNPs met the significance level ( $\mathrm{p}<0.001)$ after Bonferroni correction for multiple comparisons. Conclusions: $A B I$ differences by race were small and although statistically significant, may not be clinically significant. Change in ABI over time varies by race and may be modified by education. Results suggest that higher education may influence the lifestyle and behavioral choices contributing to better ABI in both Blacks and Whites. Further studies are needed to confirm this observation.
\end{abstract}

\section{Keywords}

Ankle-Brachial Index, ARIC, Paraoxonase, PAD, Peripheral Artery Disease, 
SNP, Single Nucleotide Polymorphism

\section{Introduction}

Peripheral artery disease (PAD) occurs most often in the lower extremities and is the third leading cause of atherosclerotic cardiovascular death after coronary artery disease and stroke [1]. Risk factors for PAD include older age, high cholesterol, hypertension, diabetes and smoking [2]. The ankle-brachial index (ABI) is a reproducible and valid measure for diagnosing PAD; and has been the primary screening tool for PAD during the past few decades [2] because it is a low cost, non-invasive, office-based test [3]. By convention, ABI $<0.9$ indicates $>50 \%$ arterial stenosis whereas normal ABI ranges from $\geq 0.90$ to $<1.40$ [4] [5].

Previous studies report that ABI is a subclinical predictor of cardiovascular events [6] [7] [8] [9]. In 13,150 participants from the ARIC cohort, Gupta et al. found a $40 \%(95 \% \mathrm{CI}=1.12,1.74)$ increased risk of heart failure in those with low ABI $(<0.90)$ compared to those with normal ABI (1.01 - 1.40) [6]. Yeboah et al., in 1330 participants from the MESA cohort, found that ABI was an independent predictor of incident CHD/CVD beyond traditional risk factors for individuals of intermediate risk [7]. A meta-analysis of 16 population studies found that both low $(\leq 0.9)$ and high $\mathrm{ABI}(>1.4)$ were significant independent predictors of CVD events and recommended inclusion of $\mathrm{ABI}$ to enhance the Framingham Risk Score for CVD risk prediction [8]. In the ARIC cohort, each 0.10 decline in ABI was associated with greater increase CHD hazard in Blacks than Whites [9].

PAD is prevalent worldwide and found in all US ethnic groups [3]. Some, but not all, studies report that Blacks have a higher prevalence of PAD compared to Whites [2] [3] [10], independent of traditional cardiovascular risk factors [4] [11]. However, to our knowledge, the association between race and change in ABI over multiple time points has not been previously reported.

Genetics may modify the association between race and ABI. Oxidative damage to lipids and lipoproteins contributes to the development of atherosclerotic vascular diseases such as PAD. Previous studies report that this progression may be mitigated by paraoxonase (PON) antioxidant enzymes [12] [13] [14] through reduction in low-density lipoprotein oxidation [15]. For example, in a case study of 37 older people (mean age $69.9 \pm 9$ years) with PAD, PON1 genotype and PON1 activity were directly related to brachial flow-medicated vasodilation ( $\mathrm{p}=$ 0.0004) [15]. Furthermore, among 66 PAD patients and 8 controls, PON1 concentrations and activities were decreased in individuals with PAD [16]. However, the potential modification of any race-ABI association by genetic factors has not been reported.

The purpose of this study was to evaluate the association of Black and White race with change in ankle-brachial index over time, and to evaluate the effect of 
paraoxonase single nucleotide polymorphisms (SNPs) on this association using data from a large well-characterized sample of older men and women.

\section{Materials and Methods}

This study used data from the ARIC [17] cohort with genetic data collected through authorized access from dbGaP. The multi-site ARIC study was supported by the National Heart, Lung and Blood Institute of the National Institutes of Health; each site obtained institutional review board approval and written informed consent from study participants prior to participation. This study was approved by the University of California San Diego Human Research Protections Program (\#160359X); all analyses were performed using SAS ${ }^{\circledast}$ University Edition (SAS Institute, Cary, NC).

The Atherosclerosis Risk in Communities Study (ARIC) [17]: is a prospective cohort study investigating the etiology of atherosclerosis, examining the risk factors and progression of subclinical to clinical cardiovascular disease events conducted in 4 communities in the United States (Washington County, MD; Forsyth County, NC; Jackson, MS; and Minneapolis, MN) with each enrolling approximately 4000 participants selected by probability sampling. Secondary study objectives examined environmental and genetic risk factors leading to vascular stiffness. A total of 15,972 study participants aged 45 - 64 years consisting of Black (27\%) and White (73\%) men and women were examined at baseline and re-examined during four follow-up visits through 2013. Data for this analysis was collected at baseline (1987-1989), visit 3 (1993-1995) and visit 4 (19961998).

Participants: There were 11,992 ARIC participants (24.6\% Black; 75.4\% White) with ABI values $<1.4$ for whom PON genotyping data was available (Figure 1). Of these, the 7672 participants (5925 Whites; 1747 Blacks) who completed a baseline and at least one follow-up visit where ABI was measured, were included in the mixed effects repeated measures analysis.

Variables

Race: In the ARIC [17] study, race was categorized based on self-identification as Black or White.

Ankle-Brachial Index: Single systolic blood pressure measures were taken in one upper extremity and one lower extremity at baseline, visit 3 and visit 4 [17]; $\mathrm{ABI}$ values were calculated as the ratio of lower to upper extremity blood pressure [6] with $\mathrm{ABI}<0.9$ [23] considered diagnostic of PAD and participants with $\mathrm{ABI} \geq 1.4(\mathrm{n}=779)$ excluded from this analysis (Figure 1$)$.

Covariates: Health history, demographic characteristics (e.g., age, education, marital status), body mass index (BMI) $\mathrm{kg} / \mathrm{m}^{2}$ and results of 12 -hour fasting laboratory assays as well as measures of systolic and diastolic blood pressure were obtained at the baseline visit [17]. ARIC family history included maternal and paternal CHD events. Current marital status (yes/no), high school graduate or more education (yes/no), current cigarette smoking (yes/no) and alcohol use 
(yes/no) were assessed at baseline. Participants taking cholesterol-lowering medication or having cholesterol $>240 \mathrm{mmol} / \mathrm{L}$ were categorized as having high cholesterol [18]; those taking anti-diabetic medication or having fasting glucose $\geq 126 \mathrm{mg} / \mathrm{dl}$ were categorized as having diabetes mellitus [19] and those taking antihypertensive medications or having systolic pressure $>140 \mathrm{mmHg}$ or diastolic pressure $>90 \mathrm{mmHg}$ were categorized as hypertensive [20]. Current medication use including aspirin, anti-diabetic and antihypertensive medication and lipid lowering medication was determined by review of labelled containers [17] brought by participants to the baseline clinic visit.

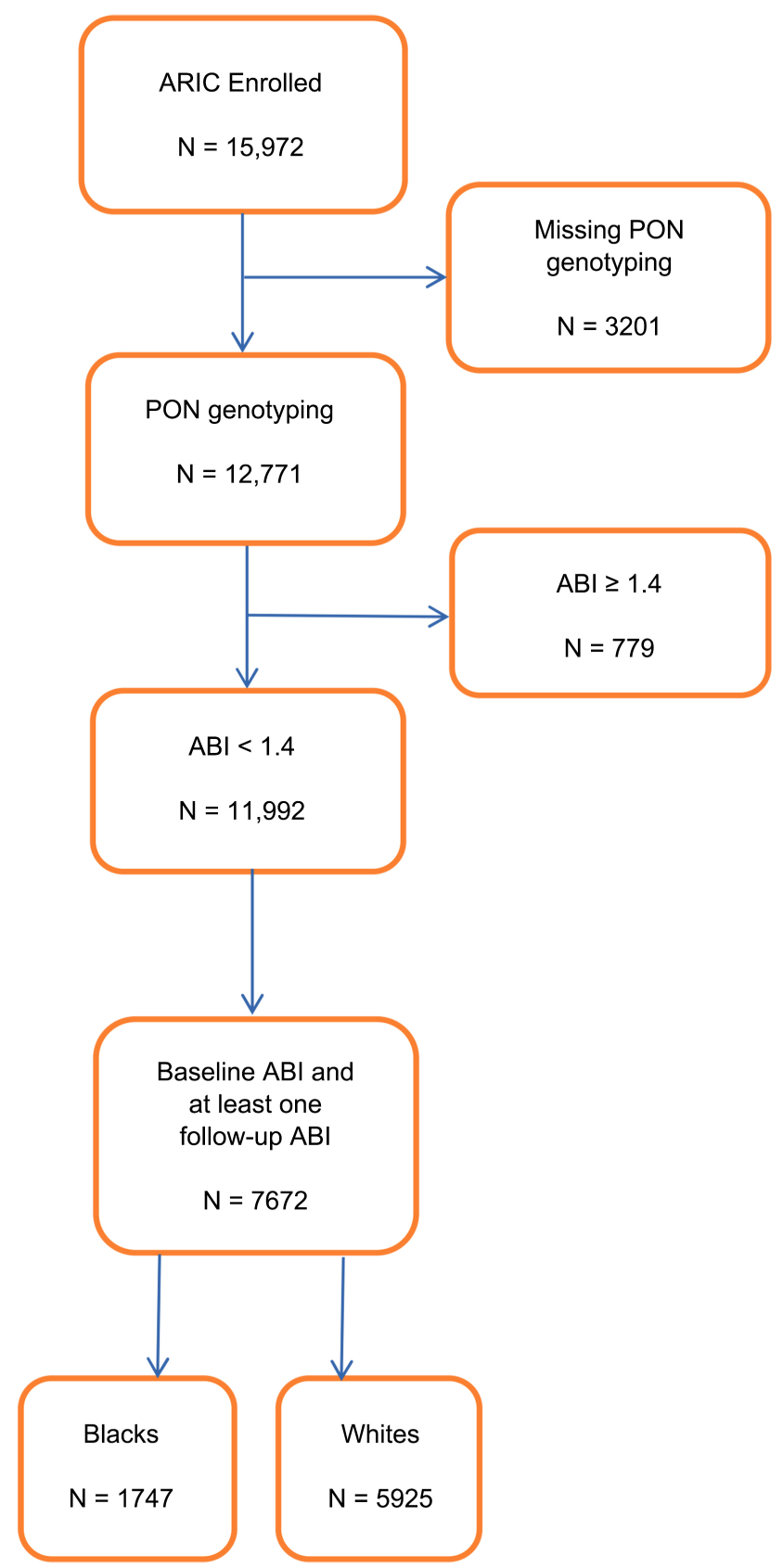

Figure 1. Flow chart sample derivation; ARIC, 1987-1989. 
Genotyping: There were 82 PON SNPs (43 PON1, 32 PON2, 7 PON3) available in the ARIC cohort which included $( \pm) 20 \mathrm{~kb}$ window around each gene region. Whole genome genotyping was performed using the Affymetrix 6.0 array platform [14]. SNPs with minor allelic frequencies (MAF) less than 5\% were excluded from the analysis, leaving 62 SNPs available for screening analysis. All SNPs were in Hardy-Weinberg equilibrium and had ancestry-specific allele frequencies similar to those reported in publicly available databases

(https://www.ncbi.nlm.nih.gov/projects/gapsolr/facets.html). The 62 SNPs were screened for significant association with PAD in Blacks and Whites combined using a significance level of $\mathrm{p}<0.001(0.05 / 45)$ after Bonferroni correction for multiple comparisons confirmed 45 independent SNPs using the Nyholt method (https://neurogenetics.qimrberghofer.edu.au/matSpDlite/). Five principal component analysis covariates obtained from the PLINK routine [21] were used to adjust for residual population stratification.

Statistical Analysis: ABI values were analyzed as a continuous variable. Baseline descriptive statistics were calculated and reported as rates for categorical data and means ( \pm standard deviations [SD]) for continuous data. Differences by race and baseline $\mathrm{ABI}$ were examined using independent $\mathrm{t}$-tests for continuous variables and chi-square analysis for categorical variables. All covariates were noncollinear as determined by a correlation coefficient of $(r<0.30)$. Covariates as well as known confounders with at least marginally significant differences by race and baseline $A B I$ were retained for further analysis. Mixed-effects models were used to assess the association between race and change in $\mathrm{ABI}$ over time as well as change in $\mathrm{ABI}$ over time within race. Results were reported as least squares (LS) means for participants with a baseline ABI and at least one follow-up (visit 3 or visit 4) ABI (mixed modelling adjusts for follow-up visit missing data). Statistical significance was defined as $\mathrm{p}<0.05$.

Covariates significantly associated with ABI $(\mathrm{p}<0.05)$ in the repeated measures model were retained for multivariable analysis. Non-significant covariates were removed using a backward step-wise model selection removing the covariate with the largest $\mathrm{p}$-value first and comparing full and reduced models. Where the likelihood ratio test was $\mathrm{p}<0.05$ and the covariates were $\mathrm{p}<0.05$, the covariate was retained in the final model. Interactions between race and covariates in the final model with $\mathrm{p}<0.05$ were considered potential effect modifiers and stratified in the final adjusted mixed-effects repeated measures model.

\section{Results}

Baseline differences between Blacks and Whites are shown in Table 1. Average baseline ABI was lower in Blacks than Whites $(1.12 \pm 0.13$ vs. $1.13 \pm 0.13$, respectively; $\mathrm{p}=0.0003)$. Compared to Whites, Black participants were younger $(54.3 \pm 5.7$ vs. $53.3 \pm 5.8$ years respectively; $\mathrm{p}<0.0001)$ and had higher mean BMI $\left(26.9 \pm 4.8\right.$ vs. $29.6 \pm 6.0 \mathrm{~kg} / \mathrm{m}^{2}$, respectively; $\left.\mathrm{p}<0.0001\right)$. There was a lower proportion of men among Black participants $(\mathrm{p}<0.0001)$ and they were less 
Table 1. Baseline characteristics by race; ARIC, 1987-1989 $(\mathrm{n}=11,992)$.

\begin{tabular}{|c|c|c|c|}
\hline & $\begin{array}{c}\text { Black } \\
(\mathrm{n}=2952)\end{array}$ & $\begin{array}{c}\text { White } \\
(\mathrm{n}=9040)\end{array}$ & \\
\hline & Mean (SD) & Mean (SD) & p-value ${ }^{*}$ \\
\hline Baseline ABI & $1.115(0.131)$ & $1.125(0.128)$ & 0.0003 \\
\hline Age (yr) & $53.3(5.8)$ & $54.3(5.7)$ & $<0.0001$ \\
\hline \multirow[t]{2}{*}{ BMI $\left(\mathrm{kg} / \mathrm{m}^{2}\right)$} & $29.6(6.0)$ & $26.9(4.8)$ & $<0.0001$ \\
\hline & $\mathrm{N}(\%)$ & $\mathrm{N}(\%)$ & \\
\hline Male & $1106(37.5)$ & $4212(46.6)$ & $<0.0001$ \\
\hline \multicolumn{4}{|l|}{ Family CVD History } \\
\hline Paternal & $531(22.1)$ & $2959(35.4)$ & $<0.0001$ \\
\hline Maternal & $397(15.0)$ & $1558(18.0)$ & 0.0002 \\
\hline Marital Status & $1745(59.9)$ & $7757(87.1)$ & $<0.0001$ \\
\hline High School Education & $1766(60.0)$ & $7534(83.4)$ & $<0.0001$ \\
\hline Current Smoking Status & $856(29.0)$ & $2229(24.7)$ & $<0.0001$ \\
\hline Current Alcohol Use & $936(32.0)$ & $5907(65.4)$ & $<0.0001$ \\
\hline Hypertension & $1625(55.3)$ & $2420(26.9)$ & $<0.0001$ \\
\hline High Cholesterol & $753(26.8)$ & $2310(25.6)$ & 0.2231 \\
\hline Diabetes & $565(19.6)$ & $776(8.6)$ & $<0.0001$ \\
\hline Aspirin & $846(29.1)$ & $4735(52.7)$ & $<0.0001$ \\
\hline
\end{tabular}

*Race differences: comparisons performed with t-tests for continuous variables, chi-square tests for categorical variables.

likely to have a paternal $(\mathrm{p}<0.0001)$ or maternal $(\mathrm{p}=0.0002)$ family history of CVD than White participants. Blacks were also less likely to use alcohol, to have completed high school education or more, to be married and to be taking aspirin (p's $<0.0001$ ); Blacks were more likely to have hypertension, diabetes and be current smokers (p's $<0.0001$ ), but there was no significant difference by race in prevalence of high cholesterol $(\mathrm{p}=0.22)$ between Black and White participants. Of the 62 PONSNPs screened, none met the criterion for statistical significance $(\mathrm{p}<0.001)$ and were therefore, not retained for further analysis (Supplemental Table A).

A mixed-effects model assessing the association between race and change in ABI over follow-up showed a significant race-time interaction (see Table 2). Additionally, among the covariates, adjusted analyses showed that older age $(\mathrm{p}<$ 0.05 ), as well as cigarette use, high cholesterol, diabetes and hypertension (p's < 0.0001 ) were each independently associated with lower ABI overall (worse), while male gender and a high school or more education were each independently associated with higher ABI overall (better) (all p $<0.0001$ ). 
Table 2. Association of race with change in ankle-brachial index; estimated coefficients from fixed effects; mixed-effect model repeated measures; ARIC, 1987-1989 ( $\mathrm{n}=7672)$.

\begin{tabular}{cccc}
\hline & Coefficient & Standard Error (SE) & p-value \\
\hline Intercept & 1.17 & 0.013 & $<0.0001$ \\
Time (Baseline) & -0.038 & 0.0027 & $<0.0001$ \\
Race (Black)* Time (Baseline) & 0.048 & 0.0062 & $<0.0001$ \\
Race (Black) & -0.030 & 0.0059 & $<0.0001$ \\
Age (per 1 yr) & -0.00046 & 0.00023 & 0.0485 \\
Gender (male) & 0.054 & 0.0025 & $<0.0001$ \\
High School Education (yes) & 0.024 & 0.0034 & $<0.0001$ \\
Cigarette Use (yes) & -0.041 & 0.0032 & $<0.0001$ \\
High Cholesterol (yes) & -0.018 & 0.0031 & $<0.0001$ \\
Diabetes (yes) & -0.031 & 0.0049 & $<0.0001$ \\
Hypertension (yes) & -0.024 & 0.0029 & $<0.0001$ \\
\hline
\end{tabular}

Reference is White race.

Figure 2 shows mean ABI by race at each visit. After adjustment for age, gender, educational status, cigarette use, high cholesterol, hypertension and diabetes, there was a difference in $\mathrm{ABI}$ of 0.018 where Whites had significantly lower $\mathrm{ABI}$ than Blacks at baseline ( $\mathrm{p}<0.0001)$, but significantly higher ( $\mathrm{p}$ 's $<0.0001)$ ABI at visits 3 and 4 (ABI difference of 0.054 and 0.030, respectively). Among Whites within race analysis showed that ABI levels significantly ( $\mathrm{p}$ 's $<0.0001$ ) increased from baseline to visit 3 and visit 4 (ABI difference of 0.042 and 0.038 , respectively). In contrast, among Blacks ABI significantly decreased by a difference of 0.012 between baseline and visit $3(\mathrm{p}<0.0001)$; the ABI difference of 0.0084 was not significantly lower at visit $4(\mathrm{p}=0.08)$.

When effect modification between race and each covariate was tested, the only significant interaction was between race and education $(p=0.02)$. Stratification by education indicated that regardless of race, participants who had completed a high school education or more (Figure 3(a)) had higher ABI than participants with less than a high school education (Figure $3(\mathrm{~b})$ ) at follow-up visits 3 and 4; however, baseline ABI values were similar regardless of education level. Among participants with a high school education or more, ABI was significantly (p's < 0.0001) higher among Whites than Blacks at both follow-up visits 3 and 4 (ABI difference of 0.060 and 0.033 , respectively). Among those without a high school education, Whites had a significantly higher ABI value of 0.039 than Blacks at the visit 3 follow-up only $(p=0.002)$ but there was no significant difference at visit $4(\mathrm{p}=0.001)$. 


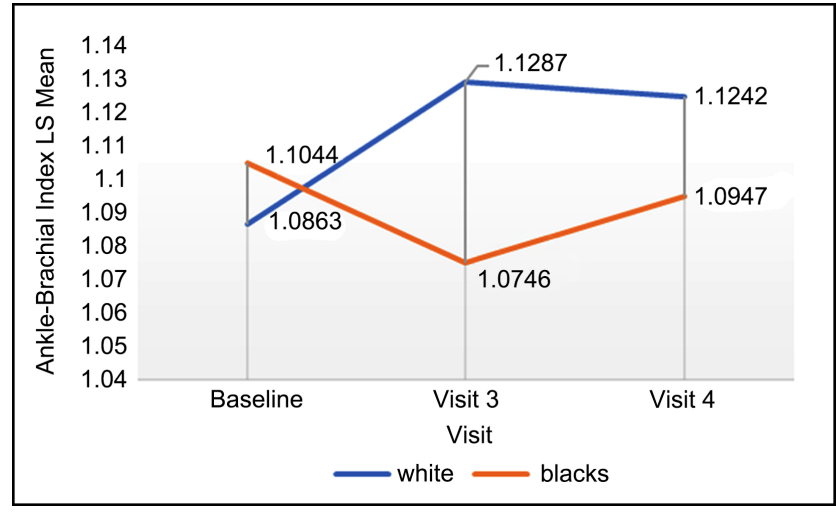

Figure 2. Race*time effects on change in ankle-brachial index $(n=7672)$; results of mixed-effect model repeated measures, ARIC baseline visit (1987-1989), visit 3 (1993-1995), visit 4 (1996-1998). LS Means = Least Squares Means; Model adjusted for race, age, gender, educational status, cigarette use, high cholesterol, diabetes and hypertension; time $(\mathrm{p}<0.0001)$, race $\mathrm{t}^{\star}$ time $(\mathrm{p}<0.0001)$; Between race ABI change difference: Baseline ( $p<0.0001)$, Visit $3(\mathrm{p}<0.0001)$, Visit $4(\mathrm{p}<0.0001)$; Within race ABI change for Whites: Visit 3 ( $\mathrm{p}<0.0001)$, Visit 4 ( $\mathrm{p}<0.0001)$; Within race ABI change for Blacks: Visit $3(\mathrm{p}<0.0001)$, Visit 4 ( $\mathrm{p}=0.0819)$; Sample size: Baseline $($ Whites $=5925$, Blacks $=1747)$, Visit 3 (Whites = 2231, Blacks =1236), Visit $4($ Whites $=4107$, Blacks $=$ 932).

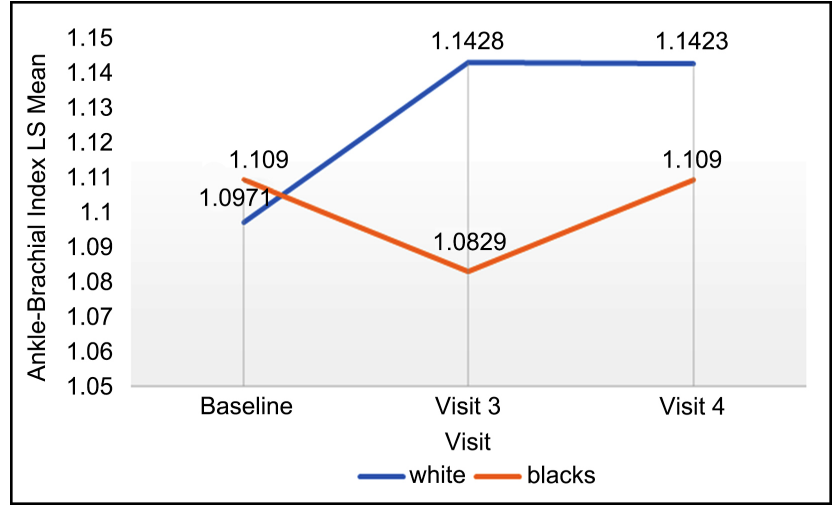

(a)

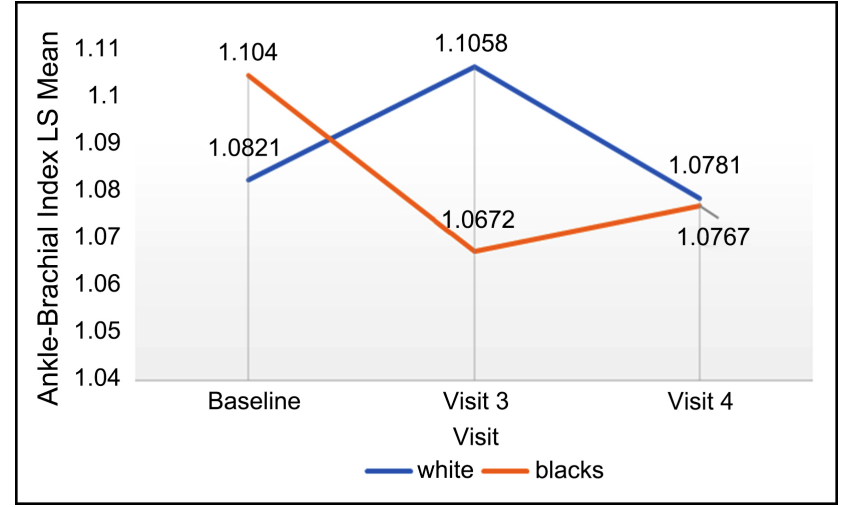

(b)

Figure 3. (a) Race ${ }^{\star}$ time effects on change in ankle-brachial index stratified by high school graduate status ( $\mathrm{n}=6166:$ high school graduates); results of mixed-effect model for repeated measures, ARIC baseline visit (1987-1989), visit 3 (1993-1995), visit 4 (1996-1998). Model adjusted for race, age, gender, cigarette use, high cholesterol, diabetes and hypertension; time ( $\mathrm{p}<$ $0.0001)$, race time $(\mathrm{p}<0.0001)$; Between race ABI change difference: Baseline $(\mathrm{p}=0.0042)$, Visit $3(\mathrm{p}<0.0001)$, Visit 4 ( $\mathrm{p}<$ 0.0001); Within race ABI change for Whites: Visit 3 ( $p<0.0001)$, Visit 4 ( $p<0.0001)$; Within race ABI change for Blacks: Visit 3 ( $\mathrm{p}<0.0001)$, Visit $4(\mathrm{p}=0.9960)$; Sample size: Baseline (Whites = 5053, Blacks = 1113), Visit 3 (Whites = 1901, Blacks = 787), Visit 4 (Whites $=3507$, Blacks = 619); (b) Race*time effects on change in ankle-brachial index stratified by high school graduate status ( $\mathrm{n}=1506$ : non-high school graduates); results of mixed-effect model for repeated measures, ARIC baseline visit (1987-1989), visit 3 (1993-1995), visit 4 (1996-1998). Model adjusted for race, age, gender, cigarette use, high cholesterol, diabetes and hypertension; time $(\mathrm{p}=0.0346)$, race ${ }^{\star}$ time $(\mathrm{p}<0.0001)$; Between race ABI change difference: Baseline $(\mathrm{p}=0.0018)$, Visit 3 ( $p=0.0003)$, Visit $4(\mathrm{p}=0.9000)$; Within race ABI change for Whites: Visit 3 ( $\mathrm{p}=0.0062)$, Visit 4 ( $\mathrm{p}=0.6106)$; Within race ABI change for Blacks: Visit $3(\mathrm{p}<0.0001)$, Visit $4(\mathrm{p}=0.0047)$; Sample size: Baseline (Whites $=872$, Blacks $=634)$, Visit $3($ Whites $=330$, Blacks $=449)$, Visit $4($ Whites $=600$, Blacks $=313)$.

\section{Discussion}

Low $\mathrm{ABI}$ has been associated with increased 10-year cardiovascular mortality rate in men and women suggesting that ABI screening may improve cardiovascular risk prediction [8]. In this longitudinal study, Whites had significantly higher 
(better) ABI values at both follow-up visits compared to baseline than Blacks after adjustment for potentially confounding covariates. However, while these racial differences were statistically significant, the ABI differences were small $(<0.15)$ [22] [23] and not likely to be clinically meaningful. Race, age, education, cigarette smoking, cholesterol, diabetes and hypertension were all significantly and independently associated with change in ABI over time. ABI over time was better in both Blacks and Whites who completed a high school education compared to those with less education. Among Whites without a high school education, ABI decreased and was similar to Blacks without a high school education by visit 4 of the follow-up period. While statistically significant, these ABI differences were small $(<0.15)$ [22] [23] and therefore may not be clinically significant. Although this study did not find significant effect modification of PON SNPs on the association between race and $\mathrm{ABI}$ over time; to our knowledge this is the first study to report results of such an evaluation. Results from this study suggest that change over time in ABI by race may be modified by education or other lifestyle factors but not by genetic factors evaluated here.

Although differences may not be clinically significant, in this sample of men and women aged 45 and older, ABI was significantly lower in Blacks (1.12) than Whites (1.13) at baseline and both follow-up visits. These results are consistent with previous studies [2] [24] of 1775 healthy participants from the MESA cohort which reported that ABI values were on average, 0.02 lower in Blacks compared to non-Hispanic Whites. Furthermore, our results are also consistent with those of Singh et al. who reported mean ABI values of 1.11 in non-Hispanic Blacks compared to 1.13 in non-Hispanic Whites in 3348 NHANES participants [24].

The association of higher educational level and better ABI has been previously reported. Aboyans et al. reported a correlation between higher education and increased ABI [2]. Additionally, a separate study of the MESA cohort reported that higher education was protective against PAD [25]. Previous studies also reported an association between education and increased risk of cardiovascular disease and hypertension. In 13,948 ARIC cohort participants [26], Kubota et al. reported that over $50 \%$ of men and women with less than high school education had a CVD event in their lifetime as compared to $42.2 \%$ of men and $28.0 \%$ of women with some college or more. These results suggest the importance of education associated with socioeconomic status, influencing access to quality health care information and its impact on decision-making towards healthier lifestyle and better health outcomes.

The effect of education on change in ABI over time in this study suggests that $\mathrm{ABI}$ is influenced more by racial disparities in risk factors and their management than racial differences in the biological development of atherosclerosis. Prior studies demonstrate that racial disparities exist with Blacks receiving lower quality health care than the majority of Whites in the United States [27] [28] [29] [30] [31]. Blacks present at a later clinical stage in the development of PAD than Whites. Furthermore, diabetes and neuropathy, both more prevalent in Blacks, 
affect the distal arteries and contribute to diagnosis of PAD [2]. In accord with this, the present study found Black race, increasing age, cigarette smoking, high cholesterol, diabetes and hypertension were associated with decreasing ABI, trending towards PAD.

The influence of genetic differences on ABI is relatively unknown. In this analysis, there was no significant effect modification of PONSNPs on the association between race and change in $\mathrm{ABI}$ over time, and to our knowledge this is the first study to examine this issue. Paraoxonase enzymes exhibit antioxidant properties and inhibit the formation and accumulation of macrophage cholesterol, thereby ameliorating the development of atherosclerosis [32]. Some studies reported positive associations between PON SNPs and PAD [33], cardiovascular disease [34] and blood pressure [32] [35]. However, other studies failed to find an association between PON polymorphisms and stroke [36] [37] or CAD [38]. This study did not find an association between PON SNPs and change in ABI over time. However, because these enzyme proteins prevent oxidative stress and inflammation, improved understanding of their influence on change over time in inflammatory diseases such as atherosclerosis, merits additional research [39].

It is plausible that there is an association between race and change in $\mathrm{ABI}$ over time due to differences in biological risk factors. Aortic stiffening may artificially lower ABI measurements and previous studies show that Blacks have a thicker and stiffer aorta compared to Whites [5]. Among the healthy participants of the MESA cohort, Aboyans et al. found that Blacks had ABI values approximately 0.2 lower than Whites [2]. However, previous research by Nicoloff et al. and Cronenwett et al. reported that an ABI decrease of $>0.15$ over time can effectively detect significant PAD progression [22] [23]. Thus, while statistically significant, the ABI differences reported in our study were less than 0.15 and may not be clinically relevant. Future studies assessing genetic differences and gene-environment interactions with respect to change in $\mathrm{ABI}$ over time need to be evaluated across diverse ethnic study populations with adequate sample size [40].

Several limitations of this study were considered. Misclassification due to selfidentified race and ascertainment of other risk factors may contribute residual confounding affecting the estimation of the association between race and ABI. $\mathrm{ABI}$ in this study may have been underestimated due to categorization based on a single measure of systolic blood pressure from one upper and one lower extremity rather than multiple measures of all extremities. Potential bias may exist due to differences between participants included and not included in the mixedeffects model analysis (data not shown). Sensitivity analyses showed that participants included in the longitudinal analyses had higher baseline ABI, lower BMI and were younger, and more likely to be married, to have completed a high school education or more and to currently use alcohol (p's $<0.0001$ ) than those excluded from the analyses. Those included in the longitudinal analyses were also less likely to be Black ( $\mathrm{p}=0.0008)$, a current smoker $(\mathrm{p}<0.0001)$, or have a diagnosis of hypertension or diabetes ( $p$ 's $<0.0001)$ than those excluded from 
the analyses potentially biasing these results toward the null hypothesis.

This study also has several strengths including the use of data from a relatively large cohort of Black and White men and women who were enrolled using a standardized protocol. It also adjusted for educational level, which has been shown to contribute to differences in diagnosis and treatment. Finally, unlike previous studies, this study examined the effects of genetics as well as the interaction between race and PAD risk factors.

Conclusions: In this study, racial differences were small and while statistically significant, may not be clinically significant. Change in ABI over time differed significantly between Blacks and Whites but was modified by education. Results suggest that compared to those without a high school diploma, ABI over time is better in both Blacks and Whites who complete a high school education or more. PON SNPs did not modify the association between race and change in ABI over time suggesting lifestyle factors rather than genetics may modify this association. Further studies are needed to confirm these observed associations and the lack of an effect of genetics on the association between race and change in ABI over time.

\section{Acknowledgements}

All authors who significantly contributed to this manuscript have been listed.

\section{Conflicts of Interest}

The authors declare no conflicts of interest regarding the publication of this paper.

\section{References}

[1] Fowkes, F.G.R., Rudan, D., Rudan, I., Aboyans, V., Denenberg, J.O., Mcdermott, M.M., Norman, P.E., Sampson, U.K.A., Williams, L.J., Mensah, G.A. and Criqui, M.H. (2013) Comparison of Global Estimates of Prevalence and Risk Factors for Peripheral Artery Disease in 2000 and 2010: A Systematic Review and Analysis. The Lancet, 382, 1329-1340. https://doi.org/10.1016/S0140-6736(13)61249-0

[2] Aboyans, V., Criqui, M.H., Mcclelland, R.L., Allison, M.A., Mcdermott, M.M., Goff Jr., D.C. and Manolio, T.A. (2007) Intrinsic Contribution of Gender and Ethnicity to Normal Ankle-Brachial Index Values: The Multi-Ethnic Study of Atherosclerosis (MESA). Journal of Vascular Surgery, 45, 319-327. https://doi.org/10.1016/j.jvs.2006.10.032

[3] Allison, M.A., Ho, E., Denenberg, J.O., Langer, R.D., Newman, A.B., Fabsitz, R.R. and Criqui, M.H. (2007) Ethnic-Specific Prevalence of Peripheral Arterial Disease in the United States. American Journal of Preventive Medicine, 32, 328-333. https://doi.org/10.1016/j.amepre.2006.12.010

[4] Allison, M.A., Cushman, M., Solomon, C., Aboyans, V., Mcdermott, M.M., Goff Jr., D.C. and Criqui, M.H. (2009) Ethnicity and Risk Factors for Change in the AnkleBrachial Index: The Multi-Ethnic Study of Atherosclerosis. Journal of Vascular Surgery, 50, 1049-1056. https://doi.org/10.1016/j.jvs.2009.05.061

[5] Greenland, P., et al. (2010) 2010 ACCF/AHA Guideline for Assessment of Cardio- 
vascular Risk in Asymptomatic Adults. Journal of the American College of Cardiology, 56, e50-e103. https://doi.org/10.1016/j.jacc.2010.09.001

[6] Gupta, D.K., Skali, H., Claggett, B., Kasabov, R., Cheng, S., Shah, A.M., Loehr, L.R., Heiss G, Nambi, G., Aguilar, D., Wruck, L.M., Matsushita, K., Folsom, A.R., Rosamond, W.D. and Solomon, S.D. (2014) Heart Failure Risk across the Spectrum of Ankle-Brachial Index: The ARIC Study (Atherosclerosis Risk in Communities). Journal of the American College of Cardiology, 2, 447-454.

https://doi.org/10.1016/j.jchf.2014.05.008

[7] Yeboah, J., Mcclelland, R.L., Polonsky, T.S., Burke, G.L., Sibley, C.T., O’Leary, D., Carr, J.J., Goff, D.C., Greenland, P. and Herrington, D.M. (2012) Comparison of Novel Risk Markers for Improvement in Cardiovascular Risk Assessment in Intermediate-Risk Individuals. JAMA, 308, 788-95.

https://doi.org/10.1001/jama.2012.9624

[8] Fowkes, F.G.R. (2008) Ankle Brachial Index Combined with Framingham Risk Score to Predict Cardiovascular Events and Mortality: A Meta-Analysis. JAMA, 300, 197208. https://doi.org/10.1001/jama.300.2.197

[9] Weatherly, B.D., Nelson, J.J., Heiss, G., Chambless, L.E., Sharrett, A.R., Nieto, F.J., Folsom, A.R. and Rosamond, W.D. (2007) The Association of the Ankle-Brachial Index with Incident Coronary Heart Disease: The Atherosclerosis Risk in Communities (ARIC) Study, 1987-2001. BMC Cardiovascular Disorders, 7, Article No. 3. https://doi.org/10.1186/1471-2261-7-3

[10] Selvin, E. and Erlinger, T.P. (2004) Prevalence of and Risk Factors for Peripheral Arterial Disease in the United States: Results from the National Health and Nutrition Examination Survey, 1999-2000. Circulation, 110, 738-743.

https://doi.org/10.1161/01.CIR.0000137913.26087.F0

[11] Criqui, M.H., Vargas, V., Denenberg, J.O., Ho, E., Allison, M., Langer, R.D., Anthony, G., Bundens, W.P. and Fronek, A. (2005) Ethnicity and Peripheral Arterial Disease: The San Diego Population Study. Circulation, 112, 2703-2707. https://doi.org/10.1161/CIRCULATIONAHA.105.546507

[12] Strzyzewski, K.W., Piorunska-Stolzmann, M., Majewski, W., Kasprzak, M. and Strzyzewski, W. (2013) Effect of Surgical Treatment on Lipid Peroxidation Parameters and Antioxidant Status in the Serum of Patients with Peripheral Arterial Disease. Disease Markers, 35, 647-652. https://doi.org/10.1155/2013/530946

[13] Arslan, C., Altan, H., Bersirli, K., Aydemir, B., Kiziler, A.R. and Denli, S. (2009) The Role of Oxidative Stress and Antioxidant Defenses in Buerger Disease and Atherosclerotic Peripheral Arterial Occlusive Disease. Annals of Vascular Surgery, 24, 455-460.

[14] Abello, D., Sancho, E., Camps, J. and Joven, J. (2014) Exploring the Role of Paraoxonases in the Pathogenesis of Coronary Artery Disease: A Systematic Review. International Journal of Molecular Sciences, 15, 20997-21010. https://doi.org/10.3390/ijms151120997

[15] Pasqualini, L., Cortese, C., Marchesi, S., Donatella, S., Pirro, M., Vaudo, G., Liberatoscioli, L., Gnasso, A., Schillaci, G. and Mannarino, E. (2005) Paraoxonase-1 Activity Modulates Endothelial Function in Patients with Peripheral Arterial Disease. Atherosclerosis, 183, 349-354. https://doi.org/10.1016/j.atherosclerosis.2005.03.030

[16] Hernandez-Aguilera, A., Sepulveda, J., Rodriguez-Gallego, E., Guirro, M., GarciaHeredia, A., Cabre, N., Luciano-Mateo, F., Fort-Gallifa, I., Martin-Paredero, V., Joven, J. and Camps, J. (2015) Immunohistochemical Analysis of Paraoxonases and Chemokines in Arteries of Patients with Peripheral Artery Disease. International Journal of Molecular Sciences, 16, 11323-11338. 
https://doi.org/10.3390/ijms160511323

[17] Atherosclerosis Risk in Communities Study (ARIC). https://www2.cscc.unc.edu/aric/desc

[18] National Heart, Lung and Blood Institute (2001) National Cholesterol Education Program: ATO III Guidelines At-A-Glance Quick Desk Reference.

[19] World Health Organization/International Diabetes Federation (2006) Definition and Diagnosis of Diabetes Mellitus and Intermediate Hyperglycemia: Report of a WHO/IDF Consultation. WHO Press, Geneva.

[20] World Health Organization, International Society of Hypertension Writing Group (2003) 2003 World Health Organization (WHO)/International Society of Hypertension (ISH) Statement on Management of Hypertension. Journal of Hypertension, 21, 1983-1992. https://doi.org/10.1097/00004872-200311000-00002

[21] Purcell, S., Neale, B., Todd-Brown, K., Thomas, L., Ferreira, M.A., Bender, D., Maller, J., Sklar, P., De Bakker, P.I., Daly, M.J. and Sham, P.C. (2007) PLINK: A Tool Set for Whole-Genome Association and Population-Based Linkage Analyses. The American Journal of Human Genetics, 81, 559-575.

https://doi.org/10.1086/519795

[22] Nicoloff, A.D., Taylor, L.M., Sexton, G.J., Schuff, R.A., Edwards, J.M., Yeager, R.A., et al. (2002) Homocysteine and Progression of Atherosclerosis Study Investigators. Relationship between Site of Initial Symptoms and Subsequent Progression of Disease in a Prospective Study of Atherosclerosis Progression in Patients Receiving Long-Term Treatment for Symptomatic Peripheral Arterial Disease. Journal of Vascular Surgery, 35, 38-46. https://doi.org/10.1016/S0741-5214(02)20052-X

[23] Cronenwett, J.L., Warner, K.G., Zelenock, G.B., Whitehouse, W.M., Graham, L.M., Lindenauer, M., et al. (1984) Intermittent Claudication: Current Results of Nonoperative Management. Archives of Surgery, 119, 430-436. https://doi.org/10.1001/archsurg.1984.01390160060012

[24] Singh, S., Bailey, K.R. and Kullo, J. (2013) Ethnic Differences in Ankle Brachial Index Are Present in Middle-Aged Individuals without Peripheral Arterial Disease. International Journal of Cardiology, 162, 228-233. https://doi.org/10.1016/j.ijcard.2011.05.068

[25] Allison, M.A., Criqui, M.H., Mcclelland, R.L., Scott, J.M., Mcdermott, M.M., Liu, K., Folsom, A.R., Bertoni, A.G., Sharrettt, A.R., Homma, S. and Kori S. (2006) The Effect of Novel Cardiovascular Risk Factors on the Ethnic-Specific Odds for Peripheral Arterial Disease in the Multi-Ethnic Study of Atherosclerosis (MESA). Journal of the American College of Cardiology, 48, 1190-1197. https://doi.org/10.1016/j.jacc.2006.05.049

[26] Kubota, Y., Heiss, G., Maclehose, R.F., Roetker, N.S. and Folsom, A.R. (2017) Association of Educational Attainment with Lifetime Risk of Cardiovascular Disease. JAMA Internal Medicine, 177, 1165-1172. https://doi.org/10.1001/jamainternmed.2017.1877

[27] Schneider, E.C., Zaslavsky, A.M. and Epstein, A.M. (2002) Racial Disparities in the Quality of Care for Enrollees in Medicare Managed Care. JAMA, 287, 1288-1294. https://doi.org/10.1001/jama.287.10.1288

[28] Institute of Medicine (2002) Unequal Treatment: Confronting Racial and Ethnic Disparities in Health Care. National Academy Press, Washington DC.

[29] Ayanian, J.Z., Weissman, J.S., Chasan-Taber, S. and Epstein, A.M. (1999) Quality of Care by Race and Gender for Congestive Heart Failure and Pneumonia. Medical Care, 37, 1260-1269. https://doi.org/10.1097/00005650-199912000-00009 
[30] Virnig, B.A., Lurie, N., Huang, Z., Musgrave, D., Mcbean, A.M. and Dowd, B. (2002) Racial Variation in Quality of Care among Medicare+Choice Enrollees. Health Affairs, 21, 224-230. https://doi.org/10.1377/hlthaff.21.6.224

[31] Kahn, K.L., Pearson, M.L., Harrison, E.R., Desmond, K.A., Rogers, W.H., Rubenstein, L.V., Brook, R.H. and Keeler, E.B. (1994) Health Care for Black and Poor Hospitalized Medicare Patients. JAMA, 271, 1169-1174. https://doi.org/10.1001/jama.1994.03510390039027

[32] Aviram, M. and Davies, K.J.A. (2004) Introduction to the Serial Review on Paraoxonases, Oxidative Stress and Cardiovascular Diseases. Free Radical Biology \& Medicine, 37, 1301-1303. https://doi.org/10.1016/j.freeradbiomed.2004.07.009

[33] Meadows, T.A., Bhatt, D.L., Cannon, C.P., Gersh, B.J., Rother, J., Goto, S., et al. (2011) Ethnic Differences in Cardiovascular Risks and Mortality in Atherothrombotic Disease: Insights from the Reduction of Atherothrombosis for Continued Health (REACH) Registry. Mayo Clinic Proceedings, 86, 960-967. https://doi.org/10.4065/mcp.2011.0010

[34] Wang, Y., Fu, W.Q., Xie, F., Wang, Y., Chu, X., Wang, H.F., Shen, M., Wang, Y., Wang, Y., Sun, WW., Lei, R., Yang, L., Wu, H., Foo, J., Liu, J.J., Jin, L. and Huang, W. (2010) Common Polymorphisms in ITGA2, PON1 and THBS2 Are Associated with Coronary Atherosclerosis in a Candidate Gene Association Study of the Chinese Han Population. Journal of Human Genetics, 55, 490-494. https://doi.org/10.1038/jhg.2010.53

[35] Fontana, V., Mcdonough, C.W., Gong, Y., Rouby, N.M., Sa, A.C.C., Taylor, K.D. Chen YDI, Gums, J.G., Chapmen, A.B., Turner, S.T., Pepine, C.J., Johnson, J.A. and Cooper-Dehoff, R.M. (2014) Large-Scale Gene-Centric Analysis Identifies Polymorphisms for Resistant Hypertension. Journal of the American Heart Association, 3, e001398. https://doi.org/10.1161/JAHA.114.001398

[36] Banerjee, I. (2010) Relationship between Paraoxonase 1 (PON1) Gene Polymorphisms and Susceptibility of Stroke: A Meta-Analysis. European Journal of Epidemiology, 25, 449-458. https://doi.org/10.1007/s10654-010-9470-4

[37] Dahabreh, I.J., Kitsios, G.D., Kent, D.M. and Trikalinos, T.A. (2010) Paraoxonase 1 Polymorphisms and Ischemic Stroke Risk: A Systematic Review and Meta-Analysis. Genetics in Medicine, 12, 606-615. https://doi.org/10.1097/GIM.0b013e3181ee81c6

[38] Gardemann, A., Philipp, M., Hess, K., Katz, N., Tillmanns, H. and Haberbosch, W. (2000) The Paraoxonase Leu-Met54 and Gln-Arg191 Gene Polymorphisms Are Not Associated with the Risk of Coronary Heart Disease. Atherosclerosis, 152, 421-431. https://doi.org/10.1016/S0021-9150(99)00489-X

[39] Precourt, L.P., Amre, D., Denis, M.C., Lavoie, J.C., Delvin, E., Seidman, E., et al. (2011) The Three-Gene Paraoxonase Family: Physiologic Roles, Actions and Regulation. Atherosclerosis, 214, 20-36. https://doi.org/10.1016/j.atherosclerosis.2010.08.076

[40] Hazarika, S. and Annex, B.H. (2017) Biomarkers and Genetics in Peripheral Artery Disease. Clinical Chemistry, 63, 236-244.

https://doi.org/10.1373/clinchem.2016.263798 


\section{Supplemental}

Table A. Association of SNP with ankle-brachial index (ABI) by race; screening results of univariate linear regression, ARIC, 1987-1989.

\begin{tabular}{|c|c|c|}
\hline & Black & White \\
\hline & p-value & p-value \\
\hline \multicolumn{3}{|l|}{ PONI SNPs } \\
\hline rs2057681 & 0.7894 & 0.6310 \\
\hline rs3917527 & 0.4994 & 0.6782 \\
\hline rs2301711 & 0.2530 & 0.7073 \\
\hline rs2299260 & 0.1074 & 0.3923 \\
\hline rs2299261 & 0.6232 & 0.6295 \\
\hline rs854568 & 0.3073 & 0.9730 \\
\hline rs 13223537 & 0.0896 & 0.3096 \\
\hline rs705378 & 0.4722 & 0.4831 \\
\hline rs 854569 & 0.5197 & 0.3072 \\
\hline rs17166829 & 0.2556 & 0.3584 \\
\hline rs3917538 & 0.1846 & 0.3160 \\
\hline rs3917521 & 0.3939 & 0.3671 \\
\hline rs854565 & 0.1920 & 0.8139 \\
\hline rs854566 & 0.2266 & 0.6749 \\
\hline rs 2237583 & 0.3296 & 0.4893 \\
\hline rs854572 & 0.8074 & 0.1119 \\
\hline rs3917541 & 0.3908 & 0.9052 \\
\hline rs3917551 & 0.4133 & 0.7229 \\
\hline rs3917550 & 0.6240 & 0.9619 \\
\hline rs2074354 & 0.6937 & 0.1549 \\
\hline rs3917490 & 0.6534 & 0.7458 \\
\hline rs2299262 & 0.5749 & 0.6456 \\
\hline rs854571 & 0.2367 & 0.6101 \\
\hline rs13236941 & 0.8623 & 0.1334 \\
\hline rs2272365 & 0.5640 & 0.1252 \\
\hline rs705382 & 0.7958 & 0.5989 \\
\hline rs2269829 & 0.9813 & 0.4547 \\
\hline rs2299257 & 0.3248 & 0.6933 \\
\hline
\end{tabular}




\section{Continued}

PON2 SNPs

\begin{tabular}{|c|c|c|}
\hline rs2299267 & 0.3821 & 0.2442 \\
\hline rs 43037 & 0.8061 & 0.6057 \\
\hline rs7778623 & 0.3718 & 0.3284 \\
\hline rs 43052 & 0.3273 & 0.4041 \\
\hline rs 4729190 & 0.7394 & 0.7811 \\
\hline rs1557782 & 0.2672 & 0.8412 \\
\hline rs 43063 & 0.4227 & 0.2230 \\
\hline rs6958904 & 0.2450 & 0.6738 \\
\hline rs2299263 & 0.2276 & 0.4817 \\
\hline rs7785039 & 0.8731 & 0.5165 \\
\hline rs3757707 & 0.7453 & 0.6976 \\
\hline rs 43061 & 0.3288 & 0.3019 \\
\hline rs 43065 & 0.1645 & 0.7556 \\
\hline rs2374993 & 0.9450 & 0.8512 \\
\hline rs10241004 & 0.1286 & 0.2341 \\
\hline rs10261470 & 0.7171 & 0.7718 \\
\hline rs10953151 & 0.2403 & 0.4992 \\
\hline rs6973380 & 0.0591 & 0.5017 \\
\hline rs10487133 & 0.3630 & 0.6179 \\
\hline rs7493 & 0.1684 & 0.4528 \\
\hline rs 12534203 & 0.6885 & 0.6980 \\
\hline rs 10953149 & 0.3882 & 0.7788 \\
\hline rs 12535571 & 0.4492 & 0.3212 \\
\hline rs1639 & 0.4128 & 0.2933 \\
\hline rs 43044 & 0.7834 & 0.7149 \\
\hline rs6950550 & 0.2243 & 0.0971 \\
\hline rs12530498 & 0.5771 & 0.1484 \\
\hline rs 43048 & 0.9265 & 0.8929 \\
\hline rs7802018 & 0.8691 & 0.9285 \\
\hline
\end{tabular}




\section{Continued}

PON3 SNPs

$\begin{array}{ccc}\text { rs468 } & 0.8689 & 0.0911 \\ \text { rs1053275 } & 0.3222 & 0.5131 \\ \text { rs11768074 } & 0.6575 & 0.7083 \\ \text { rs9641162 } & 0.4896 & 0.5634 \\ \text { rs10953143 } & 0.1363 & 0.7493\end{array}$

References: ${ }^{*} \mathrm{p}<0.001 ;{ }^{*} \mathrm{p}<0.05$. 